\title{
Bioavailability Studies of Ketorolac Tromethamine Fast Dissolving Tablets Prepared By Direct Compression Method
}

\author{
Magdy Ibrahim Mohamed ${ }^{1}$, Boushra Mohammed El-Houssieny ${ }^{2}$, \\ Maram Mourad Mansour ${ }^{2}$ M. I. Mohamed ${ }^{1}$, B. M. El-Houssieny ${ }^{2}$ and \\ M. M. Mansour ${ }^{2}$ \\ ${ }^{1}$ Professor of pharmaceutics and industrial pharmacy - Pharmaceutics department, Collage of Pharmacy, \\ Cairo University. \\ ${ }^{2}$ Professor of pharmaceutics - ex-head of pharmaceutics department, National Organization for Drug Control \\ and Research. \\ ${ }^{2}$ Assistant lecturer of pharmaceutics-Pharmaceutics department, National Organization for Drug Control and \\ Research.
}

\begin{abstract}
This study was concerned with the investigation of acute pharmacological responses (pharmacodynamics) including analgesic and anti-inflammatory effects of ketorolac tromethamine fast dissolving tablets prepared by direct compression method using $3 \%$ croscarmellose sodium as a superdisintegrant by applying tail flick test and carragenan induced rat paw edema test respectively.

Also, the work aimed to develop a sensitive LC-MS/MS method for simultaneous determination of ketorolac tromethamine in human plasma samples released from fast dissolving tablets. Also, to estimate whether the prepared tablet dosage form increases the bioavailability of ketorolac tromethamine in the body compared to marketed conventional tablet. From this study, it could be inferred that ketorolac tromethamine fast dissolving tablets (G5) containing (3\% corscarmellose sodium as a superdisintegrant, 30\% Avicel pH102, $5 \%$ aspartame, $1 \%$ talc, $1 \%$ magnesium stearate, and mannitol Q.S.) and prepared by direct compression method could be considered as a promising formula to enhance bioavilability of the drug.
\end{abstract}

Keyword: Ketorolac tromethamine fast dissolving tablet, Tail flick, Rat paw edema and bioavialbility

\section{Introduction}

Mechanism of inflammation can be studied by various investigational models of inflammatory process. Also, such models can estimate the anti-inflammatory effectiveness of different active substances ${ }^{(1)}$. Rat paw edema is one of these models in which a suspension of carrageenan is injected into the paw ${ }^{(2)}$ or pleural cavity of the rat. The paw volume either measured plethysmographically or after certain interval the animal is killed and the pleural cavity washed. Analgesic effects of anti-inflammatory drugs can be also investigated by several models. The methods used to assess the efficiency of analgesics can manipulate the interpretation of the results of experimental pain studies. Thermal methods include the hot-plate test and the tail flick test. Rodents are placed on a heated surface in the range $50-55^{\circ} \mathrm{C}$. Such temperature is as much as necessary to cause distress without tissue damage. Animals licked their forelegs and/or jumped as an indication of pain ${ }^{(3)}$. The tail flick test uses radiant heat or immersion in hot water. Mechanical methods involve the application of pressure to a digit, ear or tail and the response is noted.

HPLC coupled to a mass spectrometer (LC-MS) is very important in analysing complex sample matrices where compounds may be present in very low concentrations. Very small molecular size compounds and very large molecular size compounds are easily detected by LC-MS. LC-MS/MS is the most commonly used, due to its sensitivity, ability in detecting polar compounds and its ability to provide structural information (4). Bioavailability can be defined as the rate and extent of therapeutically active drug absorbed from the drug product, reaching the systemic circulation and become available to the site of action ${ }^{(5-6)}$.

\section{Material and methods}

\subsection{Materials}

- Ketorolac tromethaine powder was supplied by (El-Amriya Pharmaceutical Ind. Egypt )

- Fam ${ }^{\circledR}$ tablets (10 mg Acapi pharmaceutical co. Egypt ), Acetonitrail and Ammonium fumarate HPLC grade (Riedel-de Haën, Sigma-Aldrich, and GmbH. Germany)

- Carrageenan sodium (BDH, Poole. England)

- Dietheyl ether (Riedel-de Haën, Sigma-Aldrich, GmbH. Germany). 


\subsection{Animals}

Adult male Sprague Dawely albino rats of 150-170 gm body weight, six rats in each group ( four groups of rats were used ). They were used as a model animal for investigation of analgesic and antiinflammatory activity of ketorolac tromethamine. Animals were obtained from the animal house of National Center of Research. All animals were maintained under controlled environment at $20{ }^{\circ} \mathrm{C}$ with 12 hours dark / light cycle and 50-70\% relative humidity. They were fed a standard commercial rodent pellet diet and water.

\subsection{Tail flick test ${ }^{(7)}$ :}

Each animal was placed gently on the tail flick such that the tail is subjected to the IR beam. Latency to exhibit nociceptive responses, such as removing the tail was determined 30, 60, and 120 min after administration of test substances or saline using Tail flick unit (UGO, Basile, Comerio, Italy) . Saline was administered in one group ( group 1) of animals subcutaneously (s.c.) and served as a control. All drugs were injected orally 30 minutes before placing the animal on the hot plate. Treated animals in groups 2 and 3 received ketorolac tromethamine fast dissolving tablets in doses $10 \mathrm{mg}$ and $5 \mathrm{mg}$ respectively while treated animals in group 4 recieved commercial oral tablets in a dose of $10 \mathrm{mg}$

\subsection{Carrageenan induced rat paw edema test ${ }^{(8)}$ :}

One hour after the administration of the compounds, carrageenan suspension $(0.1 \mathrm{ml}$ of $1 \% \mathrm{w} / \mathrm{v}$ suspension in $0.9 \%$ saline solution) was injected into the sub planter region of left hind paw of animals. Immediately, the paw volume was measured " initial paw volume" using plethysmometer (Water plethysometer, apparatus for biological researchUGO Basile 21025 Comerio, Italy) Edema volume of control (Vc) and volume of treated $(\mathrm{Vt})$ were used to calculate percentage $(\%)$ inhibition and $(\%)$ edema volume by using the following formula :

$\%$ Inhibition $=[1-(\mathrm{Vt} / \mathrm{Vc})] \times 100$

$\%$ Edema volume $=100 \times($ Edema volume after drug treatment $]$ Initial volume

Where Vt and Vc are the increase in the volume of the carrageenan injected paws of treated and non treated control animal groups respectively.

\subsection{Statistical analysis:}

Values were expressed as means \pm S.E. Comparisons between means were carried out using one way (ANOVA) followed by least significant difference (LSD) and Tukey multiple comparisons test.

$(\mathrm{P}<0.05)$ was accepted as being significant in all types of statistical tests. SPSS software (version 17) was used for statistical analysis.

\section{Pharmacokinetic study of ketorolac tromethamine fast dissolving tablets.}

\subsection{Subject population}

Six healthy male volunteers (aged between 30-45 years) contributed in this study. Their body weights ranged from 60 to $75 \mathrm{~kg}$. Complete medical history and laboratory analysis for complete hematological and biochemical examination were done to confirm healthy condition of all volunteers. The uptake of any drug was prohibited one week prior to and during the study. Also nicotine utilization was omitted 12 hours before and 24 hours after administration of the drug.

\subsection{Study design}

The study was executed to compare pharmacokinetics of one ODT (G5) with a standard tablet (Fam $\left.{ }^{\circledR}\right)$ following administration of $(10 \mathrm{mg})$ each using non-blind, two treatments, two periods, randomized cross-over design. Under the design, half of the subjects were given G5 first treatment and (Fam $\left.{ }^{\circledR}\right)$ second treatment, and the second half of the subjects were given the treatment in the contradictory order. The subjects received the treatments at 8:00 AM of the day of study after overnight fast (at least 12 hours) as instructed before the study. From this time, they were maintained at the study room under controlled scheme for dietary and liquid intake until the study was completed. No food was allowed for 4 hours after dosing. The wash-out period was one week. The subjects were under medical control during the period of study and were observed for any adverse effects of the drug. The ODT were administrated orally without water, and each subject was asked to maintain it in the mouth for few minutes until completely dissolved in the saliva, then water was allowed after 30 minutes (treatment 1). Fam ${ }^{\circledR}$ tablet was given to the subjects with a full glass of water (about $250 \mathrm{ml}$ ) (treatment 2).

\subsection{Collection and preparation of blood samples}

Venous blood samples were collected in heparinized glass tubes after administration of the dosage form at the following time intervals $(0.083,0.166,0.25,0.5,0.75,1,1.5,2,2.5,3,4,5,6,8,10,12,16$, and 24 
hr). All samples were collected and centrifuged at 4000 r.p.m. for 10 minutes to obtain the plasma. The obtained plasma was then subjected to the following steps before injection:

1) $0.5 \mathrm{ml}$ plasma $+0.5 \mathrm{ml} \mathrm{HCL} 1 \mathrm{~N}+50 \mathrm{ul}$ (toltrodine $1 \mathrm{ug} / \mathrm{ml}$ ) $+6 \mathrm{ml}$ Diethylether.

2) Vortex, centrifuge, decant upper organic layer.

3) Evaporate under a stream of nitrogen at $50^{\circ} \mathrm{C}$.

4) Reconstitution in $0.3 \mathrm{ml}$ mobile phase

5) Inject 10 ul to $\mathrm{LC} / \mathrm{MS} / \mathrm{MS}$.

\subsection{Analytical procedures for determination of ketorolac tromethamine in plasma}

\subsection{Chromatographic conditions}

Plasma concentrations of ketorolac tromethamine were determined using simple procedure using UV detector at wave length $\left(\lambda_{\max }\right) 312 \mu \mathrm{m}$.

Mobile phase: $\quad 10 \mathrm{mM}$ amm.formate : Acetonitrile $(30: 70 \mathrm{v} / \mathrm{v})$.

Flow rate: $\quad 0.7 \mathrm{ml} / \mathrm{min}$.

Column : $\quad$ inertsil ODS $-3 \quad(5 \mathrm{um} \times 4.6 \mathrm{~mm} \times 50 \mathrm{~mm})$

Injection volume: $10 \mathrm{ul}$.

\subsubsection{Method for validation of bioavailability}

a) Selectivity

Plasma samples (six blanks) were chromatographed before use in order to test out for endogenous constituents, which might impede with ketorolac tromethamine. Spiked plasma samples representing a low, medium and high ketorolac tromethamine (QCL, QCM, and QCH, respectively) were also analysed to verify the selectivity of the analysis method.

\section{b) Linearity and linear working range}

The linearity and linear working range were determined from the constructed standard calibration curve.

\subsection{3 .Preparation of stock and working standard solutions}

Ketorolac tromethamine standard stock solution was prepared by dissolving $10 \mathrm{mg}$ of the standard drug into $100 \mathrm{ml}$ methanol.

\subsubsection{Construction of in-vivo standard calibration curve}

ketorolac tromethamine stock solution was diluted with methanol to contain $(10 \mathrm{mg})$ of the drug, by transferring $1 \mathrm{ml}$ of stock solution into centrifuge tubes provided with tight sealing polyethylene cap

Standard solutions were prepared by spiking $0.5 \mathrm{ml}$ of blank plasma over $1 \mathrm{ml}$ of each of the above standard solutions. The analytical method consisted of a single step extraction of ketrolac from plasma using a mixture of $(0.5 \mathrm{ml} \mathrm{HCL} 1 \mathrm{~N}), 50 \mathrm{ul}$ (toltrodine $1 \mathrm{ug} / \mathrm{ml})$, and $6 \mathrm{ml}$ Diethylether.

The samples were then vortexed using Vortex mixer (Paramix II, Julabo laboratechchnik, GmbH, Seelbak. Germany) for 5 minutes and centrifuged at 4000 r.p.m. for 10 minutes. The upper layer was collected and transferred to another tube, filtered through $0.45 \mu \mathrm{m}$ Millipore filter, then evaporated under a stream of nitrogen at $50{ }^{\circ} \mathrm{C}$. This was followed by reconstitution in $0.3 \mathrm{ml}$ mobile phase. Finally, $10 \mu \mathrm{l}$ were injected to the column for analysis.

\subsubsection{Plasma analysis}

Each blood sample was prepared for chromatographic assay by adding a mixture of $(0.5 \mathrm{ml} \mathrm{HCL} 1$ $\mathrm{N}), 50 \mathrm{ul}$ (toltrodine $1 \mathrm{ug} / \mathrm{ml}$ ), and $6 \mathrm{ml}$ Diethylether. The samples were then vortexed for 5 minutes and centrifuged at 4000 r.p.m. for 10 minutes. The upper layer was collected and transferred to another tube, filtered through $0.45 \mu \mathrm{m}$ Millipore filter, then evaporated under a stream of nitrogen at $50{ }^{\circ} \mathrm{C}$. This was followed by reconstitution in $0.3 \mathrm{ml}$ mobile phase. Finally, $10 \mu \mathrm{l}$ were injected to the column of analysis.

\subsubsection{Assessment of pharmacokinetic parameters ${ }^{\left({ }^{(9)}\right.}$}

For single -dose studies, pharmacokinetic data include evaluation of the plasma concentration time data for each subject, $\mathrm{Cp}_{\max }(\mu \mathrm{g} / \mathrm{ml}), \mathrm{T}_{\max }$ (hours), $\mathrm{AUC}_{(0-24)}(\mu \mathrm{g} . \mathrm{hr} / \mathrm{ml}), \mathrm{AUC}_{(0-\infty)}(\mu \mathrm{g} . \mathrm{hr} / \mathrm{ml}), \mathrm{K}\left(\right.$ hour $\left.^{-1}\right)$, $\mathrm{t}_{1 / 2}$ (hours), MRT, and $\mathbf{F}_{\text {rel }}$ were estimated using a computer program Win- Non- Lin (version 1.5, Scientific consulting, Inc, NC). 


\section{Results and discusion}

Rats treated with either the selected ketorolac tromethamine ODT formula (G5) or Fam ${ }^{\circledR}$ tablets prolonged the tail flick reaction time of the animals and demonstrated significant antinociceptive action $(\mathrm{P}<$ 0.05: statistically significant from the control) as shown in table (1). There was no significant differences between the prepared KT fast dissolving tablets and Fam ${ }^{\circledR}$ tablets $(P>0.05=0.263)$. Both tablets showed good analgesic activity but the prolonged reaction time was observed with ketorolac tromethamine ODT tablets in a dose of $10 \mathrm{mg}$.

It was apparent that injection of carrageenan induced prominent edema in all the tested animals. Moreover, there was a significant difference $(\mathrm{p}<0.05)$ between all groups receiving KT tablets and the control group as represented in tables $(2 \& 3)$. The anti-inflammatory activity of the selected ketorolac tromethamine ODT formula (G5) either in a dose of $10 \mathrm{mg}$ or $5 \mathrm{mg}$ appeared clearly from the first hour and remained till the fourth hour, while the anti- inflammatory activity of the commercial tablet Fam ${ }^{\circledR}$ was almost existed during the first hour as shown in figure (1). The results inferred that the prepared KT fast dissolving tablets gave a higher percentage of edema inhibition than the oral conventional tablets (61\% and 53\% respectively).

**Results of the validation of the analytical method revealed that

- The method was selective for ketorolac tromthamine with a minimum limit of quantification $(10 \mathrm{ng} / \mathrm{ml})$ as in figure $(2 \& 3)$.

- Excellent linearity of the calibration lines and high reproducibility of the assay method was obtained as in figure (4).

- The tested market tablets Fam ${ }^{\circledR}$ exhibited a mean peak plasma concentration of $934.185 \pm 0.707 \mathrm{ng} / \mathrm{ml}$ as illustrated graphically in figure (5), a mean $\mathrm{T}_{\max }$ of 2.5 hours, a mean AUC (0-24) of $7996.71 \pm 20.046$ ng.hr/ml, and a mean $\quad \mathrm{AUC}_{(0-\infty)}$ of $8382.82 \pm 192.781 \mathrm{ng} . \mathrm{hr} / \mathrm{ml}$ as represented in table (4) .

- The selected ODT formula (G5) showed a mean peak plasma concentration of $1220.73 \pm 0.804 \mathrm{ng} / \mathrm{ml}$ as represented graphically in figure (6 \& 7), a mean $\mathrm{T}_{\max }$ of 1 hours, a mean AUC $(0-24)$ of $10178.29 \pm 9.743$ ng.hr/ ml, and a mean $\mathrm{AUC}_{(0-\infty)}$ of $10180.804 \pm 9.743 \mathrm{ng} . \mathrm{hr} / \mathrm{ml}$ as shown in table (5).

- The relative bioavailability was found to be $127.302 \pm 0.385$ based on the mean of $\mathrm{AUC}_{(0-2)}$ of the tested formula G5 compared to that of the reference standard product.

- The statistical analysis of $\mathrm{cp}_{\max }, \mathrm{AUC}_{(0-24)}$, and $\mathrm{AUC}_{(0-\infty)}$ inferred that a significant difference $(\mathrm{p}<0.05)$ in the rate of drug absorption was found between the selected KT fast dissolving tablet formula G5 and the commercial conventional tablet Fam®.

From all the previous findings, it could be inferred that ketorolac tromethamine fast dissolving tablets (G5) containing (3\% corscarmellose sodium as a superdisintegrant, $30 \%$ Avicel $\mathrm{pH} 102,5 \%$ aspartame, $1 \%$ talc, $1 \%$ magnesium stearate, and mannitol Q.S.) and prepared by direct compression method could be considered as a promising formula to enhance bioavilability of the drug.

\section{Acknowledgment}

Thanks to Dr / Sally El-Awdan (Researcher, pharmacology department, National Research Center- El Bohoth st., Dokki) . My great gratitude to Dr / Rasha Altahawy (technical affair manager at ERDC CompanyDown town -cairo) for helping me to complete this work

\section{References}

[1]. Romay C, Ledón N, and Gonzälez R. Further studies on anti-inflammatory activity of phycocyanin in some animal modles of inflammation. Inflam.Res.1998: 334-338 .

[2]. Kumar KEE. Synthesis and anti-inflammatory activity of N-substituted dihydropyridylacetic acids, esters and amides. Drug Design Discov.1978 : 145-149

[3]. Young-Liang JIA, Zhao J, Zhang LH, et al. Analgesic and anti-inflammatory effects of ginger oil. Chines Herbal Medicines. 2011: $15-155$

[4]. Bajad S, and Shulaev V. Highly -parallel metabolismic approaches using LC-MS/MS for pharmaceutical and environmental analysis. Trend in Analytical Chemistry.2007: 625-636.

[5]. Gibaldi M. Biopharmaceutics and clinical pharmaco- kinetics. $3^{\text {rd }}$ ed. Lea \& Febiger. Philadelphia. 1984; pp131-136.

[6]. Schoenwald RD. Introduction in pharmacokinetics in drug discovery and development.3rd ed. CRC Press. London. (2002): pp 330 .

[7]. D'Amour FE, and Smith DL. A method for determining loss of pain sensation. J. Pharmacol. Exp. Ther. 1941: 74- 79 .

[8]. Winter CA, Risely E.A, and Nuss GW. Carageenan induced edema hind paw of the rats as an assay for anti inflammatory drugs. Proc. Soc. Expt. Bio. Med.1962: 544-547

[9]. Webster AA. Pharmaceutical product stability. In: Pharmaceutical sciences Encyclopedia: Drug discovery, development and manufacturing ( Webster AA ).Jon Wily and Sons, Inc.New York. 2010;pp 1-14 
Table (1): Tail flick reaction time of the selected ketorolac tromethamine fast dissolving tablets (G5) and commercial conventional tablet Fam ${ }^{\circledR}$

\begin{tabular}{|c|c|c|c|c|}
\hline \multirow{2}{*}{$\begin{array}{c}\text { Group } \\
\text { No }\end{array}$} & \multicolumn{4}{|c|}{ Tail flick reaction time after the following time intervals in minutes (Mean \pm SE) } \\
\cline { 2 - 5 } & Baseline & $\mathbf{3 0}$ & $\mathbf{6 0}$ & $\mathbf{1 2 0}$ \\
\hline Group 1 & $3.64 \pm 0.743$ & $4.34 \pm 0.344$ & $4.74 \pm 0.350$ & $5.82 \pm 0.481$ \\
\hline Group 2 & $5.22 \pm 0.333$ & $7.44 \pm 0.655^{*}$ & $10.16 \pm 0.595^{*}$ & $12.08 \pm 0.690^{*}$ \\
\hline Group 3 & $3.74 \pm 0.746$ & $5.80 \pm 0.659$ & $8.20 \pm 1.126^{*}$ & $11.34 \pm 1.763$ \\
\hline Group 4 & $2.28 \pm 0.1393$ & $4.52 \pm 0.539$ & $6.22 \pm 0.879$ & $7.54 \pm 0.643$ \\
\hline
\end{tabular}

Table (2): Anti-inflammatory activity of the selected ketorolac tromethamine fast dissolving tablets (G5) and the conventional commercial tablets (Fam®)

\begin{tabular}{|c|c|c|c|c|}
\hline \multirow{2}{*}{ Group no } & \multicolumn{3}{|c|}{$\begin{array}{c}\text { \% edema after the following time intervals in minutes } \\
\text { (Mean } \pm \text { SE) }\end{array}$} \\
\cline { 2 - 5 } & $\mathbf{6 0}$ & $\mathbf{1 2 0}$ & $\mathbf{1 8 0}$ & $\mathbf{2 4 0}$ \\
\hline Group 1 & $100 \pm 15$ & $129 \pm 8$ & $143 \pm 16$ & $131 \pm 19$ \\
\hline Group 2 & $69 \pm 14$ & $58 \pm 7^{*}$ & $55 \pm 9^{*}$ & $65 \pm 8^{*}$ \\
\hline Group 3 & $79 \pm 7$ & $77 \pm 11^{*}$ & $58 \pm 7^{*}$ & $66 . \pm 8^{*}$ \\
\hline Group 4 & $90 \pm 15$ & $78 \pm 19$ & $67 \pm 14^{*}$ & $79 \pm 17$ \\
\hline
\end{tabular}

- Values are expressed as means $\pm \operatorname{SE}(n=6)$.

* Significantly different from control group at $\mathrm{P}<0.05$.

Significantly different from reference drug group at $\mathrm{P}<0.05$.

Statistical analysis was done using one way ANOVA followed by Turkey for multiple comparisons respectively.

Table (3): (\%) Inhibition of rat paw edema for the selected ketorolac tromethamine fast dissolving tablets (G5) and the conventional commercial tablets Fam ${ }^{\circledR}$

\begin{tabular}{|c|c|c|c|c|}
\hline \multirow{2}{*}{ Group no } & \multicolumn{3}{|c|}{ \% Inhibition in edema volume after the following time intervals in minutes } \\
\cline { 2 - 5 } & $\mathbf{6 0}$ & $\mathbf{1 2 0}$ & $\mathbf{1 8 0}$ & $\mathbf{2 4 0}$ \\
\hline Group 1 & - & - & 61 & - \\
\hline Group 2 & 31 & 55 & 57 & 50 \\
\hline Group 3 & 21 & 40 & 53 & 69.39 \\
\hline Group 4 & 10 & 40 & \\
\hline
\end{tabular}

Table (4): Pharmacokinetic parameters of ketorolac tromethamine following administration of Fam ${ }^{\circledR} 10$ mg to six healthy volunteers

\begin{tabular}{|c|c|c|c|c|c|c|c|}
\hline Parameter & $\mathbf{A}$ & B & C & D & $\mathbf{E}$ & $\mathbf{F}$ & Mean \pm SD \\
\hline$C p_{\max }(\mathrm{ng} / \mathrm{ml})$ & 934.59 & 934.96 & 934.57 & 933.95 & 934.09 & 932.95 & $934.19 \pm 0.707$ \\
\hline $\mathbf{T}_{\max }(\mathrm{hr})$ & 2.5 & 2.5 & 2.5 & 2.5 & 2.5 & 2.5 & $2.5 \pm 0.00$ \\
\hline $\begin{array}{l}\mathrm{AUC}_{(0-24)} \\
\text { (ng.hr/ml) }\end{array}$ & 7999.02 & 8009.67 & 7968.49 & 8023.18 & 7978.95 & 8000.64 & $7996.71 \pm 20.046$ \\
\hline $\begin{array}{l}\text { AUC }_{(0-\infty)} \\
\text { (ng.hr/ml) }\end{array}$ & 8001.46 & 8499.77 & 8391.38 & 8523.54 & 8430.19 & 8450.56 & $\begin{array}{l}8382.82 \pm \\
192.781\end{array}$ \\
\hline$T_{1 / 2}(h r)$ & 5.629 & 5.709 & 5.506 & 5.735 & 5.880 & 5.589 & $5.626 \pm 0.085$ \\
\hline$K\left(h r^{-1}\right)$ & 0.123 & 0.121 & 0.126 & 0.121 & 0.124 & 0.124 & $0.123 \pm 0.002$ \\
\hline MRT & 7.484 & 8.452 & 8.271 & 8.474 & 8.340 & 8.348 & $8.228 \pm 0.372$ \\
\hline
\end{tabular}

Table (5): Pharmacokinetic parameters of ketorolac tromethamine following administration of an oral dose of $10 \mathrm{mg}$ of the selected ODT (G5) to six healthy volunteers

\begin{tabular}{|c|c|c|c|c|c|c|c|}
\hline Parameter & $\mathbf{A}$ & B & $\mathrm{C}$ & D & $\mathbf{E}$ & $\mathbf{F}$ & Mean \pm SD \\
\hline$C p_{\max }(n g / m l)$ & 1220.48 & 1219.96 & 1221.98 & 1220.04 & 1221.42 & 1220.48 & $1220.73 \pm 0.804$ \\
\hline$T_{\max }(\mathrm{hr})$ & 1 & 1 & 1 & 1 & 1 & 1 & $1 \pm 0.00$ \\
\hline $\operatorname{AUC}_{(0-24)}(\mathrm{ng} . \mathrm{hr} / \mathrm{ml})$ & 10168.50 & 10172.96 & 10175.92 & 10186.53 & 10193.73 & 10172.09 & $10178.29 \pm 9.743$ \\
\hline $\operatorname{AUC}_{(0-\infty)}(\mathrm{ng} . \mathrm{hr} / \mathrm{ml})$ & 10171.00 & 10175.49 & 10178.43 & 10189.05 & 10196.24 & 10174.61 & $10180.80 \pm 9.743$ \\
\hline$T_{1 / 2}(h r)$ & 5.791 & 5.847 & 5.802 & 5.817 & 5.809 & 5.820 & $5.814 \pm 0.019$ \\
\hline$K\left(h r^{-1}\right)$ & 0.119 & 0.1185 & 0.119 & 0.1191 & 0.1192 & 0.1190 & $0.1191 \pm 0.0004$ \\
\hline MRT & 7.219 & 7.235 & 7.221 & 7.233 & 7.235 & 7.223 & $7.228 \pm 0.007$ \\
\hline $\begin{array}{l}\text { \% Releative } \\
\text { bioavilability }\end{array}$ & 127.122 & 127.003 & 127.762 & 126.964 & 127.757 & 127.204 & $127.302 \pm 0.365$ \\
\hline
\end{tabular}




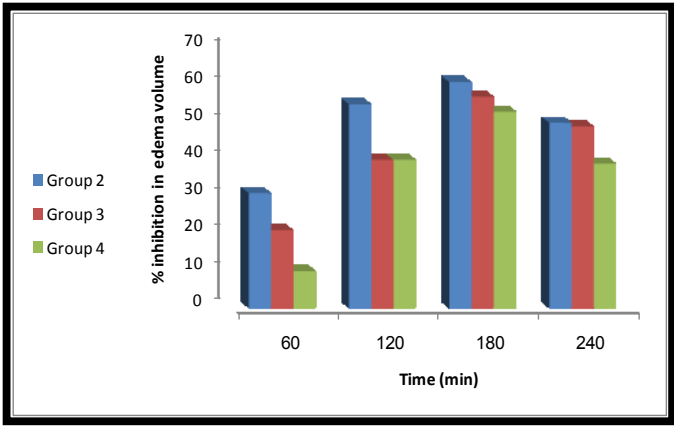

Fig (1): Anti-inflammatory efficacy of the selected ketorolac tromethamine fast dissolving tablet (G5) and the conventional commercial tablet Fam ${ }^{\circledR}$.

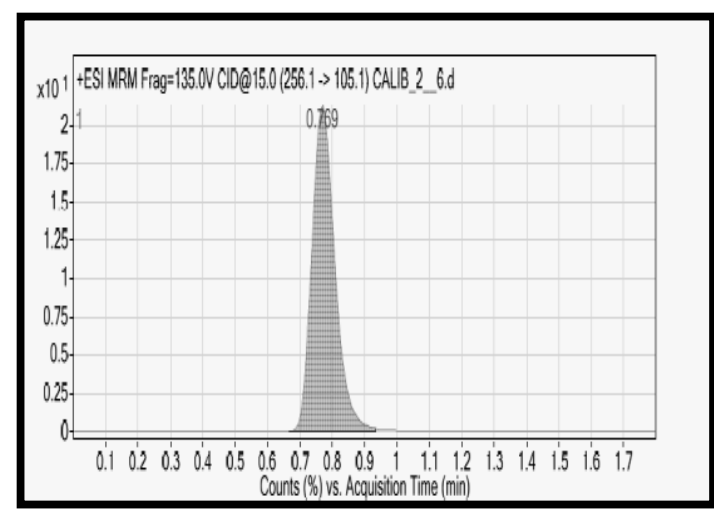

Fig (3): Medium Quality Control sample of ketorolac tromthamine tromethamine $(\mathrm{QCM})$

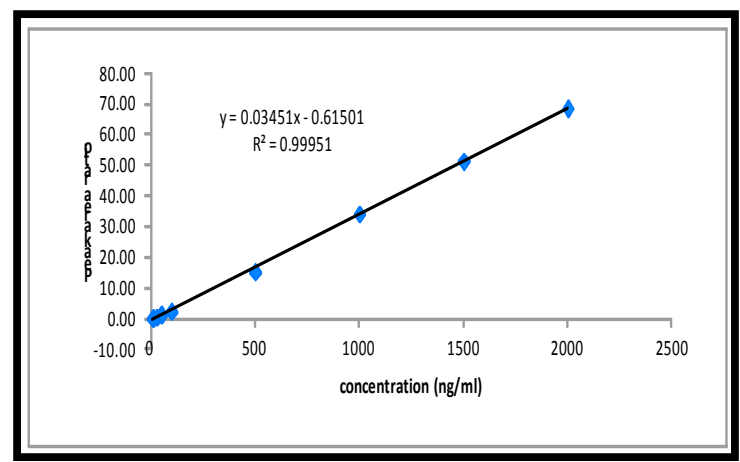

Fig (4): In-vivo standard calibration curve of ketorolac tromethamine in human plasma

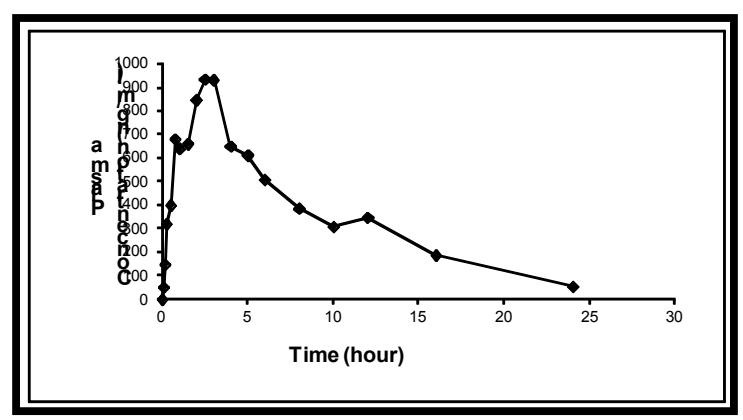

Fig (5): Plasma concentration of ketorolac tromethamine following the administration of an oral dose of Fam ${ }^{\circledR}$ tablets $10 \mathrm{mg}$ to six healthy volunteers.

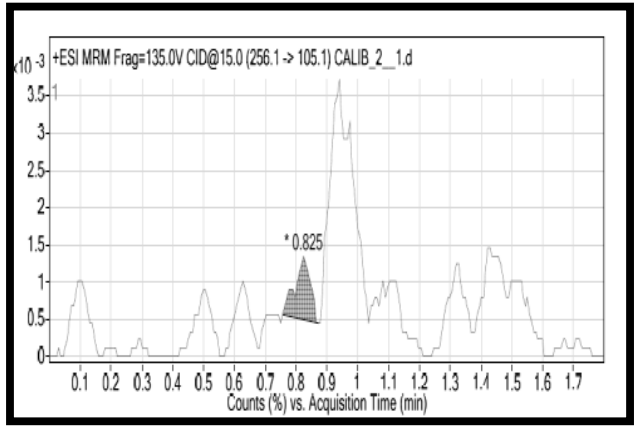

Fig(2): A typical chromatogram obtained from a processed blank human plasma

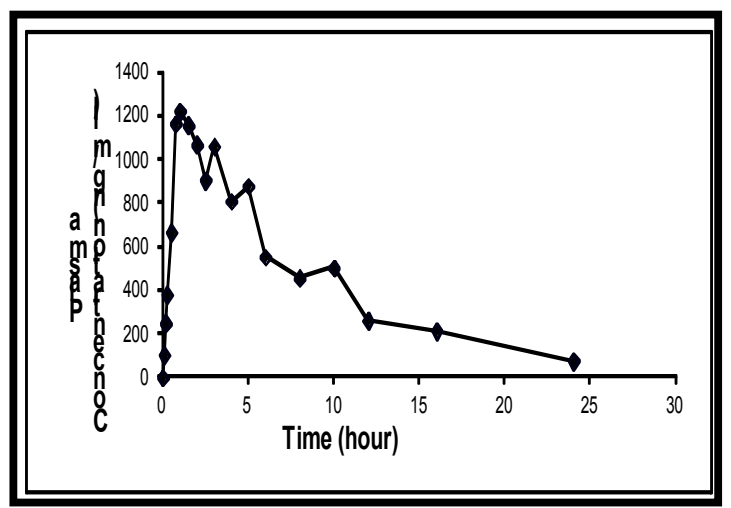

Fig (6): Plasma concentration of ketorolac following administration of an oral dose of $10 \mathrm{mg}$ of the selected ODT formula (G5) in six healty voluntears

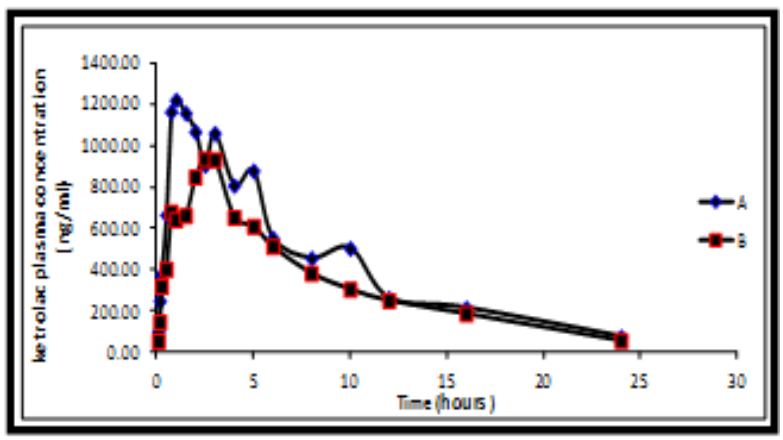

Fig(7): Mean plasma concentrations of ketorolac

tromethamine after administration of an oral dose of $10 \mathrm{mg}$ of Fam ${ }^{\circledR}$ and the selected fast dissolving tablet Formula G5 in six healthy voulntears

- A : Selected KT fast dissolving tablet formula G5

- B : Commercial conventional KT oral tablet Fam ${ }^{\circledR}$ 